\title{
Reliability of MPPT Converter in Different Operating Modes
}

\author{
B. Abdi, S. M. M. Mirtalaei, and R. Ghasemi, Member, IACSIT
}

\begin{abstract}
The reliability plays an important role in power electronic systems by which the number of system failures, repair costs, guarantee and etc are estimated. In this paper first, a boost Maximum Power Point Tracker (MPPT) converter is simulated in Discontinues Conduction Mode (DCM) and Continuous Conduction Mode (CCM) under different output power ratings. For these simulations, all of the inherent parameters of MOSFET and diodes are applied according to the actual types. Then, reliability calculation is done based on MIL-HDBK-217 standard. Results have shown that the MPPT converter would have better performance from reliability point of view in CCM operating mode.
\end{abstract} time.

Index Terms-MPPT, solar cell, photovoltaic, reliability, life

\section{INTRODUCTION}

In a photovoltaic system, the PV panel represents the most percentage of the total cost of the system, the battery storage system second expensive block and other system components such as power electronic inverters and converters contribute only a small percentage of system cost. Due to the high cost of solar cells, it is necessary to operate the PV panel at maximum power point (MPP). The maximum power produced by a solar cell changes with solar radiation and temperature as shown in Fig. 1 and Fig. 2 [1].

In order to optimize the ratio between output power and cost of installation, photovoltaic systems are supposed to draw maximum power from the modules continuously, regardless of weather conditions or load voltage. Maximum power point trackers, commonly known as MPPT, are systems that operate PV modules so that maximum power can be achieved in all radiation and temperature conditions. Fig. 3 shows a PV system includes MPPT.

The DC/DC conversion process implies in turn an associated effect of impedance transformation, i.e., the input impedance shows a dependence on a number of parameters such as load resistance, duty cycle, etc. In this sense, converters are similar to transformers. When they are used as impedance adaptors, except that in converters the adaptation parameter is not the turns ratio between the secondary and primary ones, but the duty cycle $\mathrm{D}$, which can be governed electronically, a fact that corresponds to MPPT. Different topology of DC-DC converters are used as MPPT. Comparisons between different topology of converters for

Manuscript received January 23, 2013; revised May 18, 2013.

This work was supported in part by Damavand Branch, Islamic Azad University.

The authors are with Damavand Branch, Islamic Azad University, Damavand, Tehran, Iran (e-mail: babakabdi@ieee.org).
MPPT operation are given in [2]-[6].

Buck and Boost are suitable topologies [7]. Boost topology is selected in this paper for investigation.

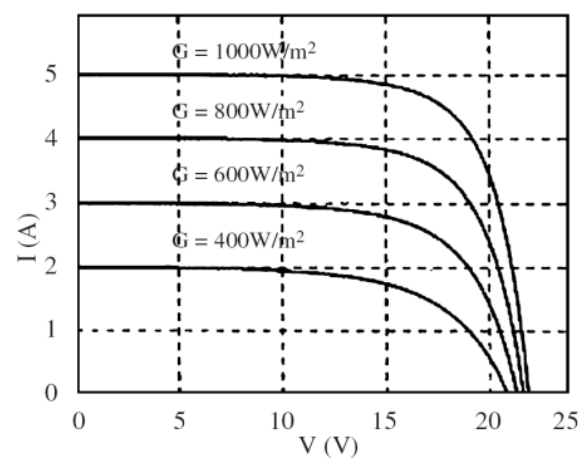

Fig. 1. Power generation in a solar cell versus solar radiation.

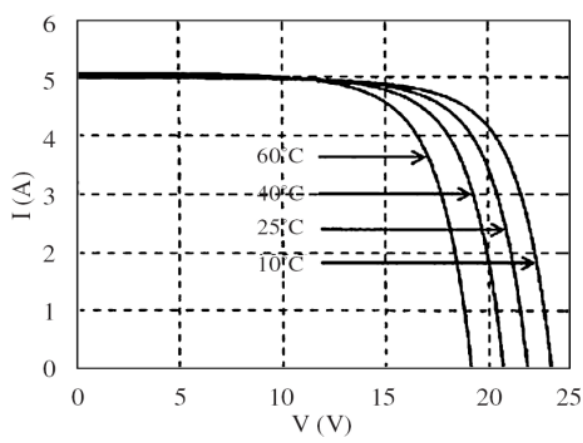

Fig. 2. Produced power in a solar cell versus temperature.

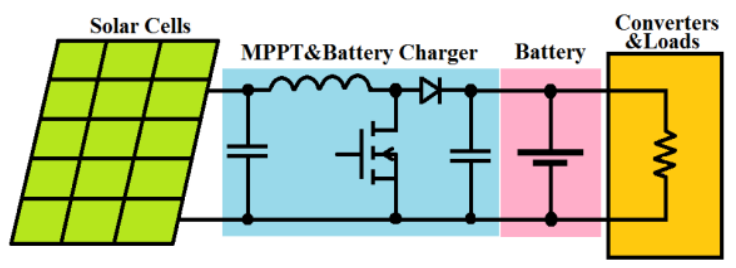

Fig. 3. A PV system including boost MPPT converter.

In switch mode converters the main filter inductor can operate in either continues or discontinues conduction mode. Performance comparison of CCM and DCM fly-back converters are given in [8]. Aspects being compared were component stress, output voltage regulation and transient response due to step load and efficiency.

The comparison was carried out experimentally on a $5 \mathrm{~V} / 25 \mathrm{~W}, 50 \mathrm{kHz}$ prototype CCM and DCM fly-back converters which have been designed and built with similar circuit lay outs, components and power ratings. Tests performed on the prototype converter have shown that devices in the CCM fly-back converter sustain the same voltage stress, but less current stress than its DCM counterpart, when delivering the same output power. 
TABLE I: CONVERTERS PARAMETERS

\begin{tabular}{|c|c|c|c|c|c|c|}
\hline \multirow{2}{*}{$\begin{array}{l}\text { Output } \\
\text { power } \\
\text { Operatin } \\
\text { g mode }\end{array}$} & \multicolumn{2}{|c|}{$300 \mathrm{~W}$} & \multicolumn{2}{|c|}{$600 \mathrm{~W}$} & \multicolumn{2}{|c|}{$1000 \mathrm{~W}$} \\
\hline & $\mathrm{CCM}$ & DCM & $\mathrm{CCM}$ & $\mathrm{DCM}$ & $\mathrm{CCM}$ & DCM \\
\hline \multirow[b]{2}{*}{ MOSFET } & $\begin{array}{c}I X F H \\
15 N 80 Q\end{array}$ & $\begin{array}{c}I X F H \\
15 N 80 Q\end{array}$ & $\begin{array}{c}I X F H \\
15 N 80 Q\end{array}$ & $\begin{array}{c}I X F H \\
15 N 80 Q\end{array}$ & $\begin{array}{c}A P T 8043 \\
\text { BFLL }\end{array}$ & $\begin{array}{c}\text { APT8043 } \\
\text { BFLL }\end{array}$ \\
\hline & $\begin{array}{l}V_{n}=1200 \mathrm{~V} \\
I_{n}=15 \mathrm{~A} \\
R_{D s}(\text { on })=0.6 \Omega \\
\theta_{j c}=0.42^{\circ} \mathrm{C} / \mathrm{W}\end{array}$ & $\begin{array}{l}V_{n}=1200 \mathrm{~V} \\
I_{n}=15 \mathrm{~A} \\
R_{D_{s}}(\text { on })=0.6 \Omega \\
\theta_{j c}=0.42^{\circ} \mathrm{C} / \mathrm{W}\end{array}$ & $\begin{array}{l}V_{n}=1200 \mathrm{~V} \\
I_{n}=15 \mathrm{~A} \\
R_{D \sigma}(o n)=0.6 \Omega \\
\theta_{j c}=0.42^{\circ} \mathrm{C} / \mathrm{W}\end{array}$ & $\begin{array}{l}V_{n}=1200 \mathrm{~V} \\
I_{n}=15 \mathrm{~A} \\
R_{D s}(\text { on })=0.6 \Omega \\
\theta_{j c}=0.42^{\circ} \mathrm{C} / \mathrm{W}\end{array}$ & $\begin{array}{l}V_{n}=800 \mathrm{~V} \\
I_{n}=20 \mathrm{~A} \\
R_{D z}(o n)=0.43 \Omega \\
\theta_{j c}=0.31^{\circ} \mathrm{C} / \mathrm{W}\end{array}$ & $\begin{array}{l}V_{n}=800 \mathrm{~V} \\
I_{n}=20 \mathrm{~A} \\
R_{D z}(\text { on })=0.43 \Omega \\
\theta_{j c}=0.31^{\circ} \mathrm{C} / \mathrm{W}\end{array}$ \\
\hline \multirow[b]{2}{*}{$\begin{array}{l}\text { output } \\
\text { Diode }\end{array}$} & DSIE12 & DSIE 12 & DSIE12 & DSIE12 & DSIE12 & DSIE12 \\
\hline & $\begin{array}{l}V_{n}=1200 \mathrm{~V} \\
V_{f}=2.6 \mathrm{~V} \\
\theta_{j c}=1.6^{\circ} \mathrm{C} / \mathrm{W}\end{array}$ & $\begin{array}{l}V_{n}=1200 \mathrm{~V} \\
V_{f}=2.6 \mathrm{~V} \\
\theta_{j c}=1.6^{\circ} \mathrm{C} / \mathrm{W}\end{array}$ & $\begin{aligned} V_{n} & =1200 \mathrm{~V} \\
V_{f} & =2.6 \mathrm{~V} \\
\theta_{j c} & =1.6^{\circ} \mathrm{C} / \mathrm{W}\end{aligned}$ & $\begin{array}{l}V_{n}=1200 \mathrm{~V} \\
V_{f}=2.6 \mathrm{~V} \\
\theta_{j c}=1.6^{\circ} \mathrm{C} / \mathrm{W}\end{array}$ & $\begin{array}{l}V_{n}=1200 \mathrm{~V} \\
V_{f}=26 \mathrm{~V} \\
\theta_{j c}=1.6^{\circ} \mathrm{C} / \mathrm{W}\end{array}$ & $\begin{array}{l}V_{n}=1200 \mathrm{~V} \\
V_{f}=2.6 \mathrm{~V} \\
\theta_{j c}=1.6^{\circ} \mathrm{C} / \mathrm{W}\end{array}$ \\
\hline $\begin{array}{l}\text { Input } \\
\text { Bridge }\end{array}$ & KBPC3506 & KBPC3506 & KBPC3506 & KBPC3506 & KBPC3506 & KBPC3506 \\
\hline \multirow{2}{*}{ capacitor } & $220 \mu F$ & $330 \mu F$ & $470 \mu F$ & $560 \mu F$ & $680 \mu F$ & $2 * 470 \mu F$ \\
\hline & $450 \mathrm{~V}$ & $450 \mathrm{~V}$ & $450 \mathrm{~V}$ & $450 \mathrm{~V}$ & $450 \mathrm{~V}$ & $450 \mathrm{~V}$ \\
\hline Inductor & $1.4 \mathrm{mH}$ & $1.2 \mathrm{mH}$ & $700 \mathrm{mH}$ & $600 \mathrm{mH}$ & $400 \mathrm{mH}$ & $370 \mathrm{mH}$ \\
\hline$f_{s}$ & $25 \mathrm{kHz}$ & $25 \mathrm{kHz}$ & $25 \mathrm{kHz}$ & $25 \mathrm{kHz}$ & $25 \mathrm{kHz}$ & $25 \mathrm{kHz}$ \\
\hline
\end{tabular}

In this comparison, reliability is absent and is not considered, where as reliability is a key necessity in power electronic devices by which the life time, number of failures and associated cost are estimated. In [9], effect of leakage inductance on reduction of reliability of switching power supplies is discussed. In [10], the reliability of fuel cell DC-DC converters is calculated and optimum topology from reliability point of view is presented. In this paper, a boost converter is considered as the MPPT part of a photovoltaic system. Then the simulation and reliability calculation of boost converter in DCM and CCM modes operating in three different power ratings is done. Reliability calculation is based on MIL-HDBK217 standard and in part counting method [11].

\section{DEFINITION OF RELIABILITY}

Probability of proper function of a system after a time interval is referred to as its reliability, which is dependent on the type and quality of the parts and materials used in the device, tension each part endures, the ambient conditions in which the device is working, etc. The failure rate in most of electronic systems is constant and is represented by $\lambda$; the reliability is expressed by:

$$
R(t)=e^{-\lambda t}
$$

The mathematical mean of $R(t)$ occurs at:

$$
t=\frac{1}{\lambda}
$$

Which is the amount of time that should elapse until the first failure occurs. This is called the Mean Time to Failure (MTTF). The mean time to repair (MTTR) of the system is negligible compared to MTTF, so the mean time between failures (MTBF) of a system is expressed as:

$$
M T B F=M T T R+M T T F=\frac{1}{\lambda}
$$

The total rate of the system failure is the sum of the failure rates of all parts of the system:

$$
\lambda_{\text {system }}=\sum_{n=1}^{N} \lambda_{\text {part }}
$$

Hence, the reliability of the system will be the product of all the system components' reliabilities [6]:

$$
R_{\text {system }}=\prod R_{\text {part }}
$$

\section{SimULATION RESUlTS}

To compare MPPT application of boost converter in DCM and CCM operating modes from reliability point of view, the boost converter shown in Fig. 1 is considered. The converter is simulated for three output power of $300 \mathrm{~W}, 600 \mathrm{~W}, 1000 \mathrm{~W}$ and for two operating modes of CCM and DCM using ORCAD software. In order to equalize simulation results to actual results, all of the inherent parameters of MOSFET and diodes are applied according to the actual types. The simulation parameters for different output powers and operating modes are shown in Table I. It should be mentioned that to achieve overlap waveforms of voltage and current at turn-on/turn-off instants, maximum step time of simulation is considered as $1 \mathrm{~ns}$. Simulation results of the converter in different output powers and CCM/DCM operating modes is shown in Table II. Voltage and current waveform of main switch and diode are shown in Fig. 4. It is noticeable that voltage and current are shown on a unit picture for overlap monitoring.

\section{RELIABILITY CALCULATIONS}

In this section, reliability of the boost converter in $1000 \mathrm{~W}$ output power and CCM operating mode is calculated and presented in details. For different output powers and operating modes, results of reliability calculations are shown in Table III. The part counting method [11] is used to calculate reliability. In this approach, first the failure rate of 
each element in the converter structure is obtained individually and then the value of the converter's MTBF is calculated from equation (4) that " $\mathrm{N}$ " is the number of consisting parts.

For these calculations the following assumptions are made:

- The ambient temperature is $27^{\circ} \mathrm{C}$.

- The control structures of these converters are the same as the control circuit used in [9] whose reliability is also calculated in [9].

To calculate the reliability, first the dynamic and static losses of MOSFET and Diodes should be calculated for different output powers working in two operating modes of DCM and CCM. The dynamic loss of input bridge diodes can be neglected. But, the important point that should be noted here is that if the converter is operating in DCM mode, then before further turn-on of the switch, the inductor current is reached to zero. So, there will not be the turn-on loss. Vice versa, in CCM operating mode, since in turn-on instant for the switch, the current should be transferred from diode to the switch, then the dynamic loss includes both turn-on/turn-off losses.

The peak of turn-on/turn-off loss is calculated by equation (6).

$$
P=V_{\text {avg }} \times I_{\text {avg }} \times t_{\text {ol }} \times f_{s}
$$

where $V_{\text {avg }}$ and $I_{\text {avg }}$ are the average voltage across the switch and the average current follows through the switch during turn-on/turn-off overlap times respectively. $t_{o l}$ is the turn-on/turn off overlap duration and $f_{s}$ is the switching frequency of the circuit. Using equation (6) and considering Fig. 4, the peak of turn-on/turn-off losses of MOSFET during overlap time is calculated for $1000 \mathrm{~W}$ output power in DCM and CCM operating modes as below:

In CCM operating mode:

$$
\begin{aligned}
& P_{\text {loss }(\text { Turn-off })}=\frac{400}{2} \times \frac{190}{25} \times \frac{794}{40000}=30.17 \mathrm{~W} \\
& P_{\text {loss (Turn-on) }}=\frac{400}{2} \times \frac{150}{25} \times \frac{311}{40000}=9.33 \mathrm{~W}
\end{aligned}
$$

In DCM operating mode:

$$
P_{\text {loss }(\text { Turn-off })}=\frac{400}{2} \times \frac{350}{25} \times \frac{780}{40000}=54.6 \mathrm{~W}
$$

TABLE II. SiMULATION RESULTS FOR DifFERENT OUTPUT POWERS IN DCM AND CCM OPERATING MODES

\begin{tabular}{|l|c|c|c|c|c|c|}
\hline \multicolumn{1}{|c|}{ Output power } & \multicolumn{3}{|r|}{$300 \mathrm{~W}$} & \multicolumn{2}{|r|}{$600 \mathrm{~W}$} & \multicolumn{2}{|r|}{$1000 \mathrm{~W}$} \\
\hline Operating mode & CCM & DCM & CCM & DCM & CCM & DCM \\
\hline$P_{\text {dynamic }}(M O S F E T)(W)$ & 7.5 & 15 & 15 & 25.5 & 25 & 45.5 \\
\hline$P_{\text {static }}($ MOSFET $)(W)$ & 0.486 & 1.26 & 1.94 & 3.75 & 3.9 & 9.5 \\
\hline$P_{\text {dynamic }}$ (output Diode $)(W)$ & 0.75 & 0.75 & 1.25 & 1.25 & 2.35 & 1.8 \\
\hline$P_{\text {static }}($ output Diode $)(W)$ & 3 & 3.25 & 6 & 6.25 & 10 & 10.5 \\
\hline$P_{\text {lass }}$ (input Bridge $)(W)$ & 3.26 & 4.1 & 6 & 7.25 & 8.4 & 12.6 \\
\hline Efficiency $\%$ & 93.2 & 90.6 & 93.8 & 92 & 94.1 & 91.5 \\
\hline
\end{tabular}

The values calculated above for the turn-on/turn-off losses are the peak of these losses (at $5 \mathrm{msec}$ ) that should be integrated in duration of the input voltage frequency $(50 \mathrm{~Hz})$.
This integration is done by the ORCAD software and the average dynamic losses during one cycle of input voltage $(50 \mathrm{~Hz})$ are brought in Table II.

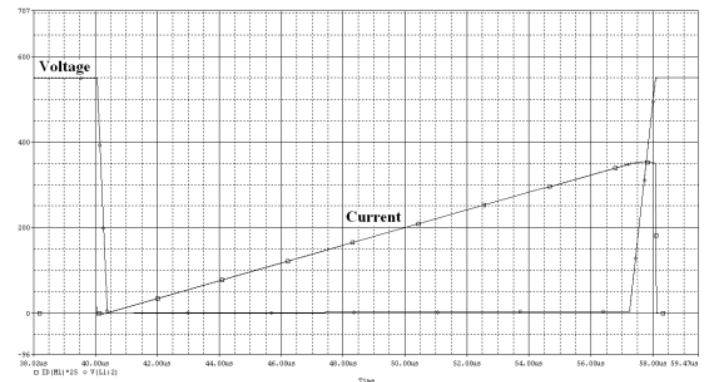

(a)

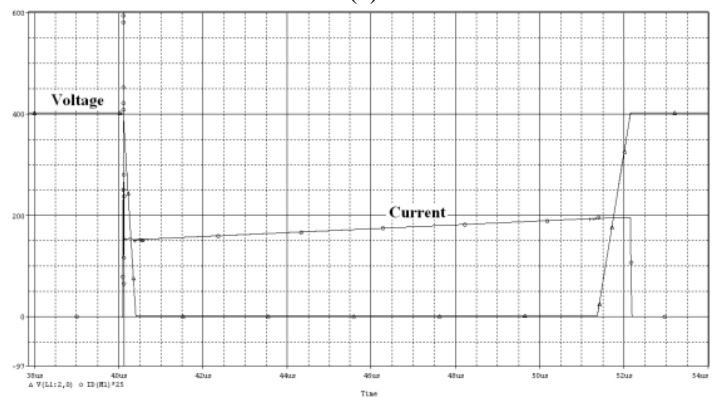

(b)

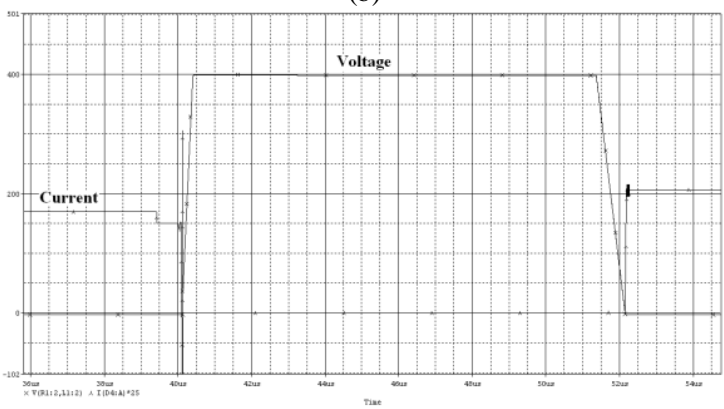

(c)

Fig. 4. Voltage and current overlap waveforms of: (a) OSFET in $1000 \mathrm{~W}$ output power and CCM operating mode. (b) MOSFET in $1000 \mathrm{~W}$ output power and DCM operating mode. (c) Output Diode in $1000 \mathrm{~W}$ output power and CCM operating mode.

Now, the failure rate of each part can be calculated as below:

A. Calculation of Failure Rate $(\lambda p)$ for MOSFET (APT8043BFLL):

$$
\begin{gathered}
V_{n}=80 \mathrm{~V}, \theta_{j c}=0.31^{\circ} \mathrm{c} / \mathrm{w}, P_{\text {loss }}=28.9 \mathrm{~W} \\
T_{c}=T_{a}+\theta_{c a} \times P_{\text {loss }}=27+1 \times 28.9=55.9^{\circ} \mathrm{C} \\
T_{j}=T_{c}+\theta_{j c} \times P_{\text {loss }}=55.9+0.31 \times 28.9=64.86^{\circ} \mathrm{C} \\
\pi_{T}=\exp \left(-1925 \times\left(\frac{1}{T_{j}+273}-\frac{1}{298}\right)\right)=2.14 \\
\lambda_{b}=0.012, \pi_{E}=6, P_{\text {out }}=310 \mathrm{~W} \Rightarrow \pi_{A}=10, \\
\pi_{Q}=5.5 \\
\lambda_{P}=\lambda_{b} \times \pi_{Q} \times \pi_{A} \times \pi_{E} \times \pi_{T} \\
\left.=0.012 \times 5.5 \times 10 \times 6 \times 2.14=8.48 \quad \text { (failure } / 10^{6} \mathrm{~h}\right)
\end{gathered}
$$


B. Calculation of Failure Rate for Output Diode (DSIE12):

$$
\begin{gathered}
V_{n}=1200 \mathrm{~V}, \quad \theta_{j c}=1.6^{\circ} \mathrm{C} / \mathrm{w}, P_{\text {loss }}=12.4 \mathrm{~W} \\
T_{c}=T_{a}+\theta_{c a} \times P_{\text {loss }}=27+1 \times 12.4=39.4^{\circ} \mathrm{C} \\
T_{j}=T_{c}+\theta_{j c} \times P_{\text {loss }}=39.4+1.6 \times 12.4=59.25^{\circ} \mathrm{C} \\
\pi_{T}=\exp \left(-1925 \times\left(\frac{1}{T_{j}+273}-\frac{1}{293}\right)\right)=2.17 \\
\lambda_{b}=0.069, \pi_{E}=6, \pi_{Q}=5.5, \pi_{C}=1 \\
V_{S}=\frac{400}{1200}=0.33 \Rightarrow \pi_{S}=V_{S}^{2.43}=0.07 \\
\lambda_{P}=\lambda_{b} \times \pi_{E} \times \pi_{Q} \times \pi_{C} \times \pi_{S} \times \pi_{T} \\
=0.069 \times 6 \times 5.5 \times 1 \times 0.07 \times 2.17=0.35\left(\text { failure } / 10^{6} \mathrm{~h}\right)
\end{gathered}
$$

C. Calculation of Failure Rate for Input Bridge:

$$
\begin{gathered}
V_{n}=1200 \mathrm{~V}, \quad \theta_{j c}=1.6^{\circ} \mathrm{C} / \mathrm{w}, P_{\text {loss }}=8.4 \mathrm{~W} \\
T_{c}=T_{a}+\theta_{c a} \times P_{\text {loss }}=27+1 \times 8.4=35.4^{\circ} \mathrm{C} \\
T_{j}=T_{c}+\theta_{j c} \times P_{\text {loss }}=35.4+1.6 \times 8.4=48.84^{\circ} \mathrm{C} \\
\pi_{T}=\exp \left(-1925 \times\left(\frac{1}{T_{j}+273}-\frac{1}{293}\right)\right)=1.8 \\
\lambda_{b}=0.069, \pi_{E}=6, \pi_{Q}=5.5, \pi_{C}=1 \\
V_{S}=\frac{400}{1200}=0.33 \Rightarrow \pi_{S}=V_{S}^{2.43}=0.07 \\
=0.069 \times 6 \times 5.5 \times 1 \times 0.07 \times 1.8=0.29\left(\text { failure } / 10^{6} \mathrm{~h}\right)
\end{gathered}
$$

D. Calculation of Failure Rate for Inductor:

$$
\begin{gathered}
T_{H S}=T_{a}+1.1 \times \Delta T=27+1.1 \times 1.5=28.65^{\circ} \mathrm{C} \\
\lambda_{b}=0.0016 \times \exp \left(\frac{T_{H S}+273}{329}\right)^{15.6}=2.2 \times 10^{-3} \\
\pi_{Q}=30, \pi_{E}=6 \\
\lambda_{p}=\lambda_{b} \times \pi_{E} \times \pi_{Q}=2.2 \times 10^{-3} \times 6 \times 30=0.39 \quad\left(\text { faulure } / 10^{6} \mathrm{~h}\right)
\end{gathered}
$$

E. Calculation of Failure Rate $\left(\lambda_{P}\right)$ for Capacitor:

$$
\begin{gathered}
\pi_{c v}=0.34 \times C^{0.18}=0.34 \times(680)^{0.18}=1.1 \\
S=\frac{400}{450}=0.89, \quad T_{A}=27^{\circ} C \\
\lambda_{b}=0.00254\left[\left(\frac{S}{0.5}\right)^{3}+1\right] \exp \left[5.09 \times\left(\frac{T_{A}+273}{358}\right)^{5}\right]
\end{gathered}
$$

$$
\begin{aligned}
& \lambda_{b}=0.14, \quad \pi_{Q}=10, \quad \pi_{E}=2, \pi_{c r}=1.1 \\
& \lambda_{p}=\lambda_{b} \times \pi_{Q} \times \pi_{E} \times \pi_{c v} \\
& =0.14 \times 10 \times 2 \times 1.1=3.08 \quad\left(\text { failure } / 10^{6} h\right)
\end{aligned}
$$

F. Failure Rate of Control Circuit Is Calculated in [4] and Is:

$$
\lambda_{P(\text { control circuit })}=0.8858 \quad\left(\text { failure } / 10^{6} h\right)
$$

TABLE III: RESULTS OF RELIABILITY CALCULATIONS FOR DIFFERENT OUTPUT POWERS IN CCM/DCM OPERATING MODES

\begin{tabular}{|l|c|c|c|c|c|c|}
\hline \multicolumn{1}{|c|}{ Output power } & \multicolumn{2}{|c|}{$300 \mathrm{~W}$} & \multicolumn{2}{c|}{$600 \mathrm{~W}$} & \multicolumn{2}{c|}{$1000 \mathrm{~W}$} \\
\hline Operating mode & CCM & DCM & CCM & DCM & CCM & DCM \\
\hline$\lambda_{p}$ (MOSFET $)$ (failure $/ 10^{6}$ hours $)$ & 7.04 & 11.24 & 9.07 & 14.18 & 8.48 & 14.32 \\
\hline$\lambda_{p}$ (output Diode $)$ (failure $/ 10^{6}$ hours $)$ & 0.26 & 0.26 & 0.3 & 0.3 & 0.35 & 0.35 \\
\hline$\lambda_{p}$ (input Bridge) (failure $/ 10^{6}$ hours $)$ & 0.25 & 0.27 & 0.29 & 0.29 & 0.29 & 0.35 \\
\hline$\lambda_{p}$ (output Capacitor $)$ (failure $/ 10^{6}$ hours $)$ & 2.52 & 2.96 & 2.88 & 2.97 & 3.08 & 3.25 \\
\hline$\lambda_{p}$ (input Inductor $)$ (failure $/ 10^{6}$ hours $)$ & 0.37 & 0.37 & 0.38 & 0.38 & 0.39 & 0.39 \\
\hline MTBF (hours $)$ & 95785 & 66225 & 77399 & 55187 & 79428 & 53590 \\
\hline
\end{tabular}

\section{DisCUSSION OF RESULTS}

Considering Table III, the following points can be concluded:

- The boost converter has higher reliability in CCM operating mode than in DCM operating mode.

- According to results, it can be seen that in all of output power ratings and both of DCM/CCM operating modes, switches has the highest failure rate in the converter structure. So, enough attention must be paid to them.

- Switches have higher failure rate in DCM mode than CCM modes. Since, in DCM mode, the peak and rms values of current is higher that results in higher current stress on switches in this mode. So, failure rate is higher in DCM mode.

\section{CONCLUSION}

In this paper, a boost MPPT converter is simulated under three output power ratings and CCM/DCM operating modes. Then, reliability calculation of the converter is done based on MIL-HDBK-217 and in part counting method. Results have shown that switches have the highest failure rate in the converter structure in both CCM/DCM operating modes and different output powers. Since the peak and rms values of current are higher in DCM mode, then the switch sustains higher current stress in DCM mode, resulting in higher failure rate in this operating mode. So, the converter has better performance in CCM operating mode.

\section{REFERENCES}

[1] T. Tafticht, K. Agbossou, M. L. Doumbia, and A. Che' riti, “An improved maximum power point tracking method for photovoltaic systems ," in Renewable Energy, Elsevier, 2008.

[2] J. M. Enrique, E. Dura'n, M. Sidrach-de-Cardona, and J. M. Andu' jar, "Theoretical assessment of the maximum power point tracking efficiency of photovoltaic facilities with different converter topologies," Trans. on Solar Energy, Elsevier, 2006.

[3] J. A. Baroudi, V. Dinavahi, and A. M. Knight, "A review of power converter topologies for wind generators," Trans. on Renewable Energy, Elsevier, 2007.

[4] K. A. Tafticht, M. L. Doumbia, and A. Che' riti, "An improved maximum power point tracking method for photovoltaic systems," Trans. on Renewable Energy, Elsevier, 2007. 
[5] N. Kasa, T. Iida, and L. Chen, "Flyback inverter controlled by sensorless current MPPT for photovoltaic power system," IEEE Trans. on Industrial Electronics, vol. 52, no. 4, August 2005.

[6] W. D. Xiao, N. Ozog, and W. G. Dunford, "Topology study of photovoltaic interface for maximum power point tracking," IEEE Trans. on Industrial Electronics, vol. 54, no. 3, June 2007.

[7] J. L. Santos, F. Antunes, A. Chehab, and C1'cero Cruz, "A maximum power point tracker for PV systems using a high performance boost converter," Trans. on Solar Energy, Elsevier, 2006.

[8] S. Howimanporn and C. Bunlaksananusorn, "Performance comparison of Continuous Conduction Mode (CCM) and Discontinuous Conduction Mode (DCM) flyback converter," IEEE, 2003.

[9] B. Abdi, M. B. Menhaj, L. Yazdanparast, and J. Milimonfared, "The effect of the transformer winding on the reliability of switching power supplies," IEEE, 2006.

[10] B. Abdi, A. H. Ranjbar, J. Milimonfared, and G. B. Gharehpetian, "Reliability calculation of fuel cell DC-DC converters and determination of optimal topology from reliability point of view," in IEEE Proc. PED's 27-30, November 2007.

[11] "Reliability prediction of electronic equipment," MIL-HDBK-217.

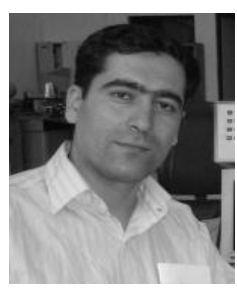

Babak Abdi was born in Tehran in 1976. He received his M.S. and Ph.D. degree in electrical engineering in 2005 and 2009 from Amirkabir University of Technology (Tehran Polytechnic), Tehran, Iran, respectively. He is currently a member of IEEE and a faculty member of Damavand branch, Islamic Azad University, Tehran, Iran. His research interests include power electronics, application of reliability in power electronics, Electromagnetic
Interferences (EMI), and electrical machines and drives.

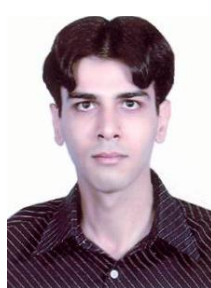

Sayyed Mohammad Mehdi Mirtalaei was born in Shahreza-Isfahan, Iran in 1983. He received his B.S. degree in electrical engineering from Isfan University of Technology, Iran in 2005. He received his M.S. and $\mathrm{Ph} . \mathrm{D}$. in electrical engineering from Amirkabir University of Technology, Tehran, Iran in 2007 and 2012 respectively. His research interest are power electronics, EMI/EMC and numerical method in electromagnetic.

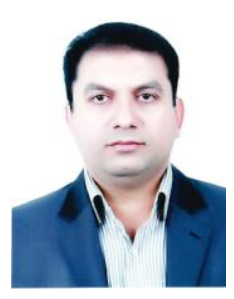

Reza Ghasemi was born in Tehran, Iran in 1979. He received his B.Sc. degree in Electrical engineering from Semnan University in 2000. He received the M.Sc. and the Ph.D. degree in control engineering from Amirkabir University of Technology, Tehran, Iran in 2004 and 2009, respectively. His research interests include large-Scale Systems, adaptive control, robust control, nonlinear control, and intelligent systems. Reza Ghasemi joined the Department of Electrical Engineering, Damavand Branch, Islamic Azad University, Tehran, Iran, where he is currently an assistant professor of electrical engineering. 